\title{
Component skills that underpin listening comprehension and reading comprehension in learners with English as first (EL1) and additional language (EAL)
}

\begin{abstract}
Aims: The primary of this study is to augment our understanding of the component skills that underpin second language learners' text comprehension by examining the direct and indirect role of vocabulary knowledge and grammatical skills in second language learners' both listening and reading comprehension. Methods: Our sample included 134 learners with English as additional language (EAL) and 74 with English as first language (EL1) $\left(\mathrm{M}_{\mathrm{age}}=123.76, S D=5.02\right.$ months).

Results: Our path analyses underscored the central role of English vocabulary and grammar in EAL learners' text comprehension. Both made independent and direct contributions to EAL learners' listening and reading comprehension levels. There were also indirect relations between vocabulary and grammar and reading comprehension through listening comprehension. Similar results were observed for the EL1 group. We also found an association between weaknesses in EAL learners' vocabulary and grammatical skills and their underperformance on listening comprehension and reading comprehension.

Conclusions: EAL learners' oral language, listening comprehension, and reading comprehension development should be examined in tandem and beyond the primary school years to clarify the long term implications of the observed EAL gap at primary school levels. Finally, our findings suggest that both vocabulary knowledge and grammatical skills need to be targeted to support children's listening and reading comprehension. This is important for both EAL and EL1 learners but particularly for the former whose English oral language skills may lag behind those of their EL1 peers.
\end{abstract}

Keywords: Listening comprehension; Reading comprehension; English as a second language (ESL); vocabulary; grammar. 


\section{Component skills that underpin listening and reading comprehension in children with English as first}

\section{(EL1) and additional language (EAL)}

With the steady increase in the number of children who speak English as an additional language (EAL), the reading research has also begun to shift to second-language learners in the UK, but many questions remain to be clarified. According to the school census report, EAL learners form about one-fifth $(20.6 \%)$ of all primary school age pupils in England and this ratio is increasing by about 0.5 percentage points per annum (Department for Education, 2017). Although some EAL learners perform well on national curriculum tests in the UK (Strand, Malmberg, \& Hall, 2015), national tests taken at the end of primary school at 11 years of age indicate a persistent EAL gap in reading comprehension (Department for Education, 2016). The level of English language proficiency has been identified as a major factor in EAL achievement gap (Demie, 2017; Whiteside, Gooch, Holloway, \& Norbury, 2016). However, current understanding of the oral language skills that underpin EAL text comprehension remains highly limited. The present study aims to address this gap by examining the direct and indirect role of English vocabulary knowledge and grammatical skills in EAL learners' both listening and reading comprehension.

\section{Oral language skills that underpin listening and reading comprehension}

The simple view of reading describes reading comprehension as a product of decoding (i.e., word recognition) and linguistic comprehension (i.e., listening comprehension) (Gough \& Tunmer, 1986). A key assumption of the simple view is that word recognition and listening comprehension are separable. Gough and Tunmer (1986) also argue that word recognition and listening comprehension show a different developmental trajectory in their relation with reading comprehension: word recognition is more strongly associated with reading comprehension in beginner readers, whereas listening comprehension becomes the dominant predictor of reading comprehension in advanced readers who can decode words with high levels of accuracy. Hence unlike decoding, listening comprehension seems to have a long-lasting role in explaining individual variations in reading comprehension. Many studies have provided support for this view (Adlof, Catts, \& Little, 2006; Curtis, 1980; Gough, Hoover, \& Peterson, 1996; Hoover \& Gough, 1990). However, 
the simple view of reading does not provide a detailed account of which component skills underpin listening comprehension or underlie its relation to reading comprehension.

The current research evidence highlights the importance of an augmented simple view of reading which takes into account specific component skills of comprehension for a better understanding of both listening and reading comprehension processes such as reading fluency, working memory, morphological and syntactic skill (Farnia \& Geva, 2013; Geva \& Farnia, 2012; Gottardo, Mirza, Koh, Ferreira, \& Javier, 2018; Hogan, Adlof, \& Alonzo, 2014; Lervåg, Hulme, \& Melby-Lervåg, 2017; Perfetti, Landi, \& Oakhill, 2005). Among these vocabulary knowledge and grammar (including morphological and syntactic skills) are fundamental for processing of the meaning of sentences and formation of a mental representation of written text and have been specifically associated with reading comprehension skills (Adlof et al., 2006; Gottardo et al., 2018; NICHD, 2005). However rarely studies examine the role of these skills in both listening and reading comprehension. Instead there is a tendency to focus on vocabulary as a proxy measure of listening comprehension, which makes it difficult to evaluate the extent to which the core oral language skills (i.e., vocabulary and grammar) underlie the relations between listening and reading comprehension and the nature of these relations (for a detailed discussion, see Gottardo et al., 2018). Therefore, it is not clear whether the role of vocabulary and grammar in reading comprehension should be understood as being direct or largely indirect through their influence on listening comprehension. Furthermore, the way in which researchers assess listening comprehension also varies across studies complicating a coherent understanding of how it links to oral language and reading comprehension (for a review, see Language and Reading Research Consortium, 2017). The research on second language learners' listening comprehension is particularly limited (Gottardo et al., 2018). In one exceptional study on Spanish-English speaking learners, Proctor and colleagues (Proctor, Carlo, August, \& Snow, 2005) found that vocabulary was directly related to listening comprehension and its relation to reading comprehension was direct as well as indirect though listening comprehension. It is not clear whether including grammatical skills might have yielded different results.

Although listening and reading comprehension are likely to call on similar component skills, it is also possible that listening comprehension is more demanding than reading comprehension on the language 
processing skills. For example, listening comprehension requires online lexical and syntactic processing of rapidly changing spoken language, which unlike reading comprehension does not allow re-reading and modulation of the speed of reading (input) to adjust to text complexity. Given that listening comprehension is as important as reading comprehension for effective learning, it is crucial to examine how vocabulary and grammar, as two foundational oral language skills, relate to both listening and reading comprehension. The next question is whether there are any differences in the way in which oral language skills relate to text comprehension in EL1 and EAL groups.

\section{Comparions of oral language and text comprehension relations in EL1 and EAL groups}

The componential model of reading (Joshi\& Aaron, 2000; Joshi, Tao, \& Quiroz, 2012) extends the simple view of reading by proposing that cognitive and ecological factors interact to influence reading comprehension skills. One key ecological factor is the possible effect of pupils' language background on the relations between oral language skills and comprehension. It is currently unclear whether the relations between oral language and reading comprehension are comparable for EL1 and EAL learners, which may in turn influence the developmental trajectories in reading comprehension over time (see Farnia \& Geva, 2013). The few studies that compared the pattern and strength of these relations between the first- and second- language learners have reported mixed findings (e.g., Babayiğit, 2014, 2015; Bowyer-Crane, Fricke, Schaefer, Lervåg, \& Hulme, 2017; Lesaux, Lipka, \& Siegel, 2006; Trapman, van Gelderen, van Steensel, van Schooten, \& Hulstijn, 2014; van Gelderen et al., 2003). For example, Trapman et al. (2014) found that whereas receptive vocabulary, grammar and metacognition were strong predictors of reading comprehension in bilingual Dutch-speaking students, word reading fluency was the strongest predictor of monolingual reading comprehension. Babayiğit (2014) also reported a tendency of vocabulary and morphosyntactic skills to be more strongly related to EAL learner's reading comprehension but in a follow-up study with a larger sample of EAL learners, she did not find any reliable differences between the EAL and EL1 groups (Babayiğit, 2015). Taken together, given the inconsistent findings in this area, it is important to consider possible differential relations when comparing the component skills of text comprehension between the EL1 and EAL cohorts. Undoubtedly, identification of similarities as well as differences between first and second 
language learners is equally informative for development of theoretical models of text comprehension and education practices.

At this point, it is notable that the research interest in examining possible differential relations between oral language and comprehension is also associated with the reports of mean group differences in oral language and text comprehension. Second language learners tend to underperform relative to their native English-speaking peers on measures of English oral language and reading comprehension (MelbyLervåg \& Lervåg, 2014), which raises the question of whether these mean group differences have any bearing on the pattern and strength of relations between oral language and text comprehension.

\section{Comparison of EL1 and EAL learners' English oral language and text comprehension levels}

In a meta-analytic review study, Melby-Lervåg and Lervåg (2014) found that second-language learners tend to underperform on reading comprehension, listening comprehension (based on the measures of either vocabulary or listening comprehension) and decoding relative to their monolingual peers. The effect sizes were medium for reading comprehension, large for listening comprehension and small for decoding. However, against this broad picture, the findings from individual studies vary considerably.

Some have reported that second-language learners catch up with (Farnia \& Geva, 2011, 2013) or even outperform their monolingual peers on word reading (Bowyer-Crane et al., 2017; Burgoyne, Whiteley, \& Hutchinson, 2010) even during the early primary grades. Likewise, some have found no second-language disadvantage in reading comprehension (Lesaux, Rupp, \& Siegel, 2007; Lesaux \& Siegel, 2003). The findings in this area also seem to be influenced by the specific linguistic, sociocultural and demographic features of second language learners, as well as their educational experiences, which may vary from one country to another (Geva, 2006; Melby-Lervåg \& Lervåg, 2014). The second-language gap was reported to be the smallest in Canada and the largest in Europe (Melby-Lervåg \& Lervåg, 2014) further underscoring the need for caution when comparing findings on second language learners from different countries and educational contexts.

To clarify the second language gap in reading comprehension, several studies have specifically examined whether the second language learners' gap in reading comprehension reflects an underlying 
weakness in second language skills. Lervåg and Aukrust (2010), for instance, found that it was primarily limitations in Norwegian vocabulary knowledge that contributed to a reading comprehension gap in a group of Urdu-Norwegian speaking learners tested in the first two years of primary school. A similar developmental lag in oral language skills and concomitant slower rates of reading comprehension development have also been reported in older second-language learners (Farnia \& Geva, 2013; MancillaMartinez \& Lesaux, 2011). For example, in a UK based study with 10-year-old EAL learners, Babayiğit (2014) reported that the observed EAL gap in reading comprehension disappeared once poorer performance on English vocabulary or grammar was taken into account. It is notable that in this study EL1 and EAL groups were matched on word reading accuracy and speed, verbal memory and duration of formal schooling in England. These findings were confirmed in a subsequent study with a larger cohort of EAL learners (Babayiğit, 2015), suggesting that oral language skills could be a key factor in explaining the EAL gap in reading comprehension. Moreover, a study on Dutch-speaking bilingual learners found that controlling for weaker Ducth vocabulary of bilingual learners led to a second language advantage in reading comprehension (van Steensel et al., 2014). However, these findings are not entirely consistent. Some have found no evidence for an EAL disadvantage in reading comprehension, despite an EAL gap in English oral language skills (Bowyer-Crane et al., 2017). Although these contradictory findings may reflect task or sample differences, together they highlight the need to take into account oral language skills when evaluating the second-language learners' listening and reading comprehension levels.

\section{Current study}

There is a paucity of research on the roles of vocabulary and grammatical skills in explaining both reading and listening comprehension in EAL learners. The present study sought to address this gap by examining an augmented model of comprehension, which builds on the simple view of reading, and examines the direct and indirect relations of vocabulary and grammatical skills on listening comprehension and reading comprehension. Thereby, we also examined the extent to which vocabulary and grammar underlie the relationship between listening comprehension and reading comprehension. Drawing on the componential view of reading, which highlights the role of language background (i.e., ecological factors) in 
reading comprehension, we further examined whether the observed relations between oral language and comprehension differed between the EL1 and EAL groups. Finally, we examined whether there was an EAL gap in oral language, listening comprehension and reading comprehension skills. Hence, we sought answers to the following two main research questions.

a) What is the direct and indirect relations of vocabulary and grammatical skills with listening comprehension and reading comprehension in EAL learners? Are the pattern and strength of these relations comparable to those for EL1 learners?

b) To what extent is there an EAL gap in English vocabulary knowledge, grammatical skills, listening comprehension, and reading comprehension?

We anticipated that vocabulary and grammar would be directly related to individual variations in both listening and reading comprehension outcomes and that there would also be indirect relations between these two oral language skills and reading comprehension through listening comprehension (see Proctor et al., 2005). Finally, following the previous reports on EAL learners from similar age groups (Babayiğit, 2014, 2015; Hutchinson, Whiteley, Smith, \& Connors, 2003), we anticipated that these relationships would be similar in EL1 and EAL groups but there would be an EAL gap in English vocabulary, grammar and text comprehension.

\section{Method}

\section{Participants}

We recruited 210 children registered in Years 5 or 6 (9-10 year olds) from seven primary schools in the UK. Two children were subsequently excluded when we discovered they were recent arrivals and spoke very limited English. These children were still adjusting to a very different educational context and language, and would have needed more time before they could be assessed reliably. Hence, the data analysis was conducted on the remaining 208 children (Mean age $=123.76$ months, $S D=5.02$ months, age range= 113 to 135 months; F: M=111: 97). No other children in our final sample were reported to be recent arrivals or have been in the UK for less than two years. Inner-city state schools in Birmingham were targeted to 
provide a heterogeneous group of language minority and monolingual children. The language of instruction was English, and all schools were following the national curriculum.

Children were classified into EL1 $(n=74)$ and EAL $(n=134)$ groups based on the information they provided in a home language background questionnaire (see Supplementary Materials). This questionnaire was administered verbally to every child and our classifications were cross-checked with class teachers' records and the school records. Our questionnaire confirmed that the EL1 pupils did not have any functional knowledge of a language other than English. The EAL pupils were exposed to at least one other language in their home environment. These children formed a heterogeneous group: 86 of these children spoke in their home language most or all of the time to at least one family member; 26 children spoke in their home language some of the time to at least one family member; 24 children spoke their home language infrequently, but at least one family member sometimes addressed them in their home language and they were exposed to the home language through other family members communicating with each other (usually their parents spoke to each other in their home language most or all of the time). Twenty-seven EAL children reported to have a good level of reading or writing skills in their home language(s). Similar findings have been reported before (Babayiğit, 2014; 2015). It seems that a significant proportion of EAL learners are not literate in their home languages in England.

Most EAL pupils spoke just one additional home language (110 out of $134 ; 82 \%$ ) and 24 spoke three or more languages. Most EAL learner $(n=108 ; 81 \%)$ spoke one of the following commonly reported languages as their dominant home language: Urdu (34), Punjabi (including Mirpuri and Hindko; 26), Bengali (13), Gujarati (8), Pashto (8), Somali (7), Caribbean Creole English (7), Arabic (5). The remaining 26 children reported other South Asian, African or European languages as their dominant home language. There are over 300 minority languages spoken in England and the heterogeneity of the home languages of our sample is representative of this diversity (CILT, 2012).

We also gained information on age, sex, free school meal eligibility, duration of formal schooling in the UK, and educational support from the school records. Not all schools agreed to provide this information: 
the information on the eligibility for free school meals was gained for 147 pupils (71\%; 91 EAL, 56 EL1) and educational support for 134 pupils (64\%; 78 EAL, 56 EL1). The EL1 and EAL groups did not differ in their age distribution [EL1 mean age $=123.75$ and $S D=4.81$ months; EAL mean age $=123.77$ and $S D=5.15$ months; $t(206)=.02, p=.982]$, being in receipt of any formal or informal educational support [11 EL1 and $9 \mathrm{EAL} ; \chi^{2}(1)=1.11, p=.292$ ] or sex ratio [EL1 female: male $=38: 36$ and EAL female: male $=72: 61 ; \chi^{2}(1)=$ $0.05, p=.811]$. There were also no EAL and EL1 group differences in the rate of eligibility for receiving free school meals, $36 \%(n=33$ out of 91$)$ EAL and $41 \% \operatorname{EL1}(n=23$ out of 56$), \chi^{2}(1)=.17, p=.683$. Finally, a majority of EAL learners (107 out of 134) were reported to be attending their current schools from the beginning of primary school. This is in line with demographics of EAL learners in this study, who mostly came from long-established South Asian ethnic groups. Unfortunately, data from 27 learners were not available. Also, it was not possible to establish whether the EAL learners who did not attend their current primary school from the beginning of primary school, in fact had been attending another primary school in the UK and therefore, had received comparable duration of formal schooling in English with those of their EL1 peers.

\section{Assessments}

Children were tested on a one-to-one basis by a research assistant in a quiet area of the school. The assessments were implemented in a fixed order, across three sessions.

\section{Home language background}

A questionnaire was read aloud to each child to ascertain whether any other languages were spoken at home, which languages were spoken, and how often English and other home languages were used with each family member (see Supplementary Materials).

\section{Nonverbal reasoning}

The Matrix Reasoning subtest from the Wechsler Intelligence Scale for Children-Fourth UK Edition (Wechsler, 2004) was used to assess nonverbal reasoning skills. The standard procedures were followed: child was shown a set of pictures, which together form a cohesive pattern. One of the pictures was missing 
from the pattern and the child was asked to choose which of four alternative pictures should go into the empty space. Sample-specific Cronbach's alpha (35 items) was .93.

\section{Word Recognition}

The Single Word Reading Test 6-16 (Foster, 2007) assessed children's word recognition skills. The task was to read aloud all the words as accurately as possible from a list of 60 words with graded difficulty. Sample-specific Cronbach's alpha (60 items) was .94.

\section{Receptive Grammar}

We administered the Test of Reception of Grammar - 2 (TROG-2, Bishop, 2003). The researcher read aloud a sentence and asked the child to match this to one of four colourful pictures. The pictures are designed to test 20 different grammatical constructs including relative clause, pronouns, and prepositions (e.g., in or on). The TROG-2 uses simple vocabulary to minimise the effect of vocabulary knowledge on performance. All 80 test items were administered. Sample-specific Cronbach's alpha (80 items) was .95. Receptive Vocabulary

We administered the British Picture Vocabulary Scales-III (Dunn, Dunn, \& National Foundation for Educational Research, 2009). The researcher read aloud a word and asked the child to match this word to one of four colourful pictures. Sample-specific Cronbach's alpha (9 blocks of 12 items) was .94.

\section{Reading Comprehension}

The reading comprehension passages from Form A of the York Assessment of Reading for Comprehension (Snowling et al., 2009) were administered. Following the test guidelines, the starting level was determined by the child's word recognition score on the Single Word Reading Test 6-16 (Foster, 2007). The children were asked to read each passage aloud, which were followed by eight comprehension questions. All children read one narrative and one expository passage. The comprehension questions included questions that required making inferences as well as literal questions which required direct retrieval of information from the passages. The sample-specific Cronbach's alpha for the two most commonly read and age-appropriate passages (levels 5 and 6; 16 items, 157 children, 75\% of sample) was .94.

\section{Listening Comprehension}


We administered passages at levels three-to-six from Form B (the parallel form) of the York Assessment of Reading for Comprehension (Snowling et al., 2009). Using the parallel forms from the York Assessment of Reading for Comprehension allowed to assess listening comprehension skills using comparable passages and question formats with those for reading comprehension. Listening comprehension can be cognitively more demanding than reading comprehension, as unlike reading comprehension does not offer visual cues or the opportunity to modulate the input by adjusting reading speed or rereading. Therefore, passages from levels three-to-six with varying length and complexity were implemented to increase the task sensitivity. The researcher read aloud each passage to the child and then asked the comprehension questions (eight per passage). The child was not shown the text of the passage. This task was split across two testing sessions to avoid fatigue. The child's average score across all these passages was used in the analyses. Sample-specific Cronbach's alpha (4 passages) was .81.

A measure of word reading accuracy rate from passages was also obtained but it was not included in our analyses since the Single Word Reading Test provides a purer measure of word recognition skill independent of text processing skills. It is, however, noteworthy that the passage word reading accuracy rate and single word reading accuracy were correlated very strongly confirming the comparability of these two measures, $r=.79, p<.001$.

\section{Results}

\section{Preliminary considerations and descriptive statistics}

Table 1 shows a summary of the descriptive statistics. Except for reading comprehension, all presented data are based on raw scores (see Supplementary Materials for standard scores, Table A). It was not possible to use raw scores for reading comprehension due to the specific scoring procedure of the York Assessment of Reading for Comprehension test. In this test, children even if they are from the same age group, are presented with different levels of passages depending on their word reading accuracy levels and comprehension score on the first passage. The estimates of standard scores take into account the differences in passage levels as well as age to enable effective comparisons of scores between children who are presented with different sets of passages. For this reason and as the standardisation data included a 
representative sample of EAL children, it was more appropriate to use the standard scores for reading comprehension. The York Assessment of Reading for Comprehension test has a mean standard score of 100 and the $S D$ is 15 . The standard scores of $<70$ were converted to 69 . Ten children scored below 70 (3 EL1 and 7 EAL). Ten data points (1\% of data) were missing due to six children being absent for one or more of the testing sessions. The path analyses were conducted using Analysis of Moment Structures (AMOS 22; Arbuckle, 2013). The full maximum likelihood estimation method was used to account for missing data (Enders \& Bandalos, 2001; Kline, 2011).

\section{Mean group differences}

Table 1 summarises the mean group differences. The EL1 group showed a significant advantage in all measures apart from word recognition. The two groups performed on a par on word recognition. It is noteworthy that controlling for matrix reasoning as a measure of general cognitive ability did not eliminate the EL1 advantage in vocabulary, grammar, listening comprehension or reading comprehension (Table 1). In contrast, controlling for either vocabulary or grammar as a covariate in the ANCOVA eliminated the EAL disadvantage in reading comprehension, $F(1,201)=0.088, p=.767, \eta_{p}{ }^{2}=0.000$ and $F(1,204)=0.922, p$ $=.338, \eta_{p}{ }^{2}=0.004$, respectively. Likewise, including either vocabulary or grammar as a covariate in the ANCOVA eliminated EAL disadvantage in listening comprehension, $F(1,201)=0.257, p=.613, \eta_{p}{ }^{2}=$ 0.001 and $F(1,204)=0.173, p=.677, \eta_{p}{ }^{2}=0.001$, respectively.

Finally, as reading skills in first language may have positive effects on second language reading (e.g., Pasquarella, Chen, Gottardo, \& Geva, 2015), we explored whether there were any differences between EAL learners who reported to be able to read in their home languages $(n=27)$ and those who reported to have no reading skills in their home language $(n=70)$. The results showed no significant group differences on any measures, confirming that it was appropriate to conduct the data analyses on the whole EAL cohort (see Supplementary Materials, Table B).

\section{Bivariate Correlations}


Table 2 summarises the bivariate correlation coefficients between the measures. All correlation coefficients between oral language and text comprehension were significant in both EL1 and EAL groups. Word recognition and general cognitive ability were related to oral language and text comprehension. Age was only related to listening comprehension in the EL1 group $(r=-.31, p=.007)$. This seems to be due to a cohort effect, with EL1 Year 5 pupils performing slightly higher than those from Year 6. Therefore, age has been factored into all subsequent analyses.

\section{Path analyses}

Figure 1 depicts our hypothesised model, which was an extension of the simple view of reading and examined the direct and indirect relations of vocabulary and grammar to reading comprehension and listening comprehension. The adequacy of the model fit was evaluated by the following three indices: a nonsignificant $\chi^{2}$ value, a CFI value at or above .95 and a RMSEA value below .05 (Browne \& Cudeck, 1993). The hypothesised model in Figure 1 was a very good fit to the data from both language groups, EL1, $\chi^{2}(4)=1.894, p=.755, \mathrm{CFI}=1.000, \mathrm{RMSEA}=.000$, with $90 \% \mathrm{CI}=.000$ to $.122 ; \mathrm{EAL}, \chi^{2}(4)=4.200, p=$ $.380, \mathrm{CFI}=0.999, \mathrm{RMSEA}=.019$ with $90 \% \mathrm{CI}=.000$ to .134 . Likewise, the model fit to the combined data from the two samples was excellent, $\chi^{2}(8)=6.092, p=.637$ CFI $=1.000 ; \mathrm{RMSEA}=0.000$, with $90 \% \mathrm{CI}$ $.000-.068$. The model in Figure 1 was further validated by examining whether including direct paths from matrix reasoning to listening and reading comprehension and word recognition to listening comprehension would make any significant improvement to the model fit. Direct paths from matrix reasoning to text comprehension measures were nonsignificant for both groups and the difference in $\chi^{2}$ was also nonsignificant, $\Delta \chi^{2}(4)=0.966, p=.915$. Likewise, the direct paths from word recognition to listening comprehension were nonsignificant in both language groups and the change in model fit was nonsignificant, $\Delta \chi^{2}(2)=2.766, p=.251$. It is also noteworthy that including direct paths from the matrix reasoning to comprehension and word recognition to listening comprehension did not change the observed pattern of direct and indirect paths in Figure 1. Therefore, the model in Figure 1 was retained. 
The standardised parameter values for direct paths for both language groups are shown in Figure 2 and the unstandardised parameter estimates in Table 3. There were unique direct relations between word recognition and reading comprehension in both groups. The direct paths from vocabulary and grammar to listening comprehension were also statistically significant in both groups. However, the direct paths from vocabulary and grammar to reading comprehension were statistically significant only for the EAL group.

A bias-corrected bootstrapping procedure was implemented to compute the CIs and test the significance of the indirect effects (with 10,000 bootstrap samples) (Hayes \& Scharkow, 2013). As Table 4 shows, there were significant indirect relations between vocabulary and grammar and reading comprehension in both EL1 and EAL groups.

Next, we examined whether the observed parameter estimates (i.e., strength of relations) were significantly different between the two groups. A multi-group path analysis was conducted on the direct paths from vocabulary, word recognition, and listening comprehension to reading comprehension. Grammar was not included in this analysis due the heterogeneity of error variance (see Aguinis, Petersen, \& Pierce, 1999). The analysis revealed nonsignificant parameter differences for the direct paths from word recognition, vocabulary and listening comprehension to reading comprehension, suggesting comparable strength of relations between the EL1 and EAL groups, $\Delta \chi^{2}(1)=1.453, p=.228 ; \Delta \chi^{2}(1)=0.105, p=.746$; $\Delta \chi^{2}(1)=2.999, p=.083$, respectively.

\section{Discussion}

The purpose of this study was to add to our understanding of the component skills that underpin second language learners' text comprehension. We examined EAL learners' English vocabulary knowledge and grammatical skills and the direct and indirect relations of these two foundational oral language skills to listening and reading comprehension. The findings from the path analyses highlighted the central role of vocabulary and grammar in EAL learner's text comprehension. Both made independent and direct contributions to variations in EAL learners' listening and reading comprehension levels even when general cognitive skills and word level reading skills were taken into account. There were also indirect relations 
between oral language and reading comprehension through listening comprehension. Similar results were observed for the EL1 group. Finally, the group comparisons revealed no group differences in word reading accuracy levels but there was an EAL gap in English vocabulary knowledge and grammar, which was associated with EAL learners' lower performance on both listening comprehension and reading comprehension.

\section{Direct and indirect relations of vocabulary and grammar with text comprehension in EL1 and EAL groups}

Our hypothesised path model was an extension of the simple view of reading and examined the direct and indirect relations between oral language skills and text comprehension. The results were in accordance with those of Proctor et al. (2005) and extended their findings by showing that a) in addition to English vocabulary knowledge, grammatical skills are also directly related to both reading comprehension and listening comprehension over and above general cognitive ability and word recognition skills; and b) these two core oral language skills are also indirectly related to reading comprehension through listening comprehension.

Broadly, the path analyses for the EL1 group yielded the same pattern of results but there were some differences. Most notably, the direct relations of vocabulary and grammar with reading comprehension were not statistically significant in the EL1 group. However, our multi-group path analysis did not reveal any reliable group differences in the size of parameter estimates. Therefore, based on these results, it is not possible to conclude that vocabulary and grammar were more strongly related to EAL reading comprehension in this study. This is in accordance of the previous studies on EAL learner from similar age groups, (Babayiğit, 2015). However, our findings contrast with those of Trapman et al. (2014) who found vocabulary and grammar to be stronger predictors of reading comprehension in 13 year-old low-achieving Dutch bilingual students, when compared to their monolingual peers. Our contrasting findings may be explained by our sample, who were younger and not specifically selected for low attainments. It is possible that the main barrier to reading comprehension in monolingual poor readers is reading fluency, whereas vocabulary and grammar are relatively more important for children without reading difficulties. 
Nevertheless, a number of other factors including the distribution of the scores across the two groups and low statistical power of moderation analyses might have also contributed to these findings. So, there remains an element of uncertainty in relation to the relative strength of these relations. In contrast, our findings indicated a definite difference in oral language and text comprehension levels of EL1 and EAL groups.

\section{EL1 and EAL group differences in oral language and text comprehension}

Previous research in this area highlighted that although second-language learners may catch-up with their native English speaking peers on word reading during the first few years of primary school, it is much more difficult for them to bridge the oral language and reading comprehension gap (Babayiğit, 2014; Burgoyne et al., 2010; Farnia \& Geva, 2013; Hutchinson et al., 2003; Mancilla-Martinez \& Lesaux, 2011; Trapman et al., 2014). Our findings are in accordance with these reports. The EAL learners performed at comparable levels with their EL1 peers on word recognition but there was an EAL gap in English listening comprehension, reading comprehension, vocabulary and grammar. Most importantly, our findings extend the previous reports and show that weaknesses in vocabulary and grammar are independently associated with EAL learners' underperformance on listening and reading comprehension measures. Taken together, these findings highlight that it is essential to focus on oral language for a coherent understanding of EAL learners' listening and reading comprehension development.

\section{Study limitations and future directions}

The findings from this study should be evaluated in light of several methodological limitations. Our results are based on cross-sectional data impeding any causal inferences. It is acknowledged that once reading skills begin to develop, there is a reciprocal relation between oral language and reading skills (Nagy, Anderson, \& Herman, 1987), which remains to be fully examined in second language learners. Despite a good range of scores, there was a tendency for a ceiling effect in EL1 learners' grammar scores, so the reported relations between EL1 grammar and comprehension should be evaluated with some caution. It is also noteworthy that EL1 group's standard mean score on reading comprehension was below the national norms. This might be related to our sample, who came from inner city schools with a high percentage of children from low socioeconomic backgrounds. Nonetheless, despite their low scores the EL1 group 
outperformed the EAL group on reading comprehension and the observed magnitude of the EL1 advantage was similar to those reported in previous research (e.g., see Babayiğit, 2014, 2015).

The use of comparable materials to assess listening and reading comprehension skills is clearly important for testing the simple view of reading and comparison of listening comprehension and reading comprehension (Hoover \& Gough, 1990) and this is what the current study aimed to achieve. However, this approach has also limitations. The comprehension of a spoken text is not the same as the comprehension of a lesson spoken by a teacher. Listening comprehension of a lesson in a classroom context is more fragile to interference from normal classroom distractions and is more demanding on attentional resources (Cain \& Bignell, 2014). EAL learners may also need more cognitive resources to make inferences about unknown words and process syntactic structures incompatible with those of their home languages (Hillert \& Nakano, 2016). Therefore, listening comprehension measures based on spoken text may not capture the complexities of the cognitive processes required for effective spoken language comprehension in a classroom context or the magnitude of true differences between EL1 and EAL linguistic comprehension. Hence, there is a clear need for further research into the multifaceted nature of listening comprehension to develop a coherent theoretical model of listening comprehension that integrates the dynamics of spoken language comprehension with written text comprehension in reading research.

There are also other high-level component skills, such as inference making, understanding of text structure, comprehension monitoring, background knowledge and text schema, which are also critical for effective text comprehension but were beyond the scope of the current study (for a review, see Language and Reading Research Consortium, 2017). It remains to be investigated to what extent vocabulary and grammar relate to these high-level component skills and examine second-language listening and reading comprehension within the context of more complex models of reading comprehension (e.g., Kintsch \& Rawson, 2005; Perfetti et al., 2005; Pressley \& Gaskins, 2006).

Finally, due to the heterogeneity of minority languages (over 300 different minority languages), it remains a major challenge to assess EAL learner's home language proficiency in the UK context. 
Nonetheless, cross-linguistic research is essential to promote a better understanding of the educational needs of EAL learners from different linguistic groups.

\section{Conclusion}

The present study extends the previous reports by showing that vocabulary knowledge and grammatical skills play an important and independent role in EAL learners' both listening and reading comprehension. We also showed that vocabulary and grammar were indirectly related to reading comprehension though listening comprehension. The pattern and strength of these relations were broadly similar for the EL1 group suggesting that the theoretical models of reading comprehension that draw on the simple view of reading are likely to provide an adequate account of both EAL and EL1 reading comprehension, but it remains unclear whether more complex models of reading comprehension are comparable across the first and second language learners.

We also found that a significant proportion of EAL learners may not achieve native like proficiency in basic vocabulary and grammatical skills in English even when they reach the end of primary school. Importantly, EAL learners' weaknesses in vocabulary and grammar is related to their underperformance on listening comprehension and reading comprehension. It is notable that the observed EAL weaknesses in English oral language, listening comprehension and reading comprehension may be too subtle to be picked up in a classroom context. Hence, there is a real concern that EAL learners' language and text comprehension needs may go unrecognised and not addressed. It is now important to find out whether the observed EAL gap in oral language and text comprehension is reduced among older age groups or is a persistent gap that continues into secondary school. This clearly warrants developmental studies on EAL learners that extend beyond the primary school years.

Incidental word learning during independent reading is a major means by which school-age children develop their vocabulary skills by making inferences about word meanings (Nagy et al., 1987). It is estimated that 10-11 years old could learn between 800 to 1,200 words per year via independent reading (Nagy et al., 1987). However, weaknesses in oral language and comprehension skills may undermine 
incidental vocabulary learning and effective deployment of reading comprehension strategies such as comprehension monitoring and thereby may make it more difficult for EAL learners to catch up with their EL1 peers in oral language or text comprehension (Proctor, Dalton, \& Grisham, 2007). Therefore, facilitating the development of vocabulary and grammatical skills should be an integral part of any education programme on text comprehension for all learners and this is particularly important for learners with EAL. 


\section{Implications for Practice}

What is already known about this topic

- The studies report a tendency of learners with English as an additional language (EAL) to underperform on reading comprehension relative to their native English-speaking peers (EL1) in the UK.

- The reported EAL gap in text comprehension has been linked to limitations in oral language skills.

- Therefore, it is crucial to clarify the key oral language skills that underpin EAL learners' text comprehension.

What this paper adds

- Vocabulary and grammar are related but distinct oral language skills that are directly related to EAL learners' listening and reading comprehension in even when individual differences in word level reading skills and general cognitive ability are taken into account.

- A significant proportion of older primary school age EAL learners may not achieve native-like proficiency in English vocabulary or grammatical skills.

- There is an association between EAL learners' weaknesses in vocabulary and grammar and their underperformance on listening comprehension and reading comprehension that warrants further investigations.

\section{Implications for theory, policy or practice}

- The theoretical models of reading comprehension like the simple view of reading are likely to provide an adequate account of both EAL and EL1 reading comprehension but it remains unclear whether more complex models of reading comprehension are comparable across first and second language learners.

- Given the complex reciprocal relations among oral language, listening comprehension and reading comprehension skills, it is imperative that educational programmes target these skills in an integrated way. This is important for all leaners and particularly EAL learners whose English oral language skills may not develop on par with their EL1 peers.

- EAL learners' oral language, listening comprehension, and reading comprehension development should be examined in tandem and beyond the primary school years to clarify whether the observed EAL gap at primary school levels continues into secondary school. 


\section{References}

Adlof, S. M., Catts, H. W., \& Little, T. D. (2006). Should the simple view of reading include a fluency component? Reading and Writing, 19, 933-958. doi:10.1007/s11145-006-9024-Z

Aguinis, H., Petersen, S. A., \& Pierce, C. A. (1999). Appraisal of the Homogeneity of Error Variance Assumption and Alternatives to Multiple Regression for Estimating Moderating Effects of Categorical Variables. Organizational Research Methods, 2, 315-339. http://doi.org/10.1177/109442819924001

Arbuckle, J. L. (2013). IBM SPSS Amos 22 Crawfordvile, FL, USA: Amos Development Cooperation.

Babayiğit, S. (2014). The role of oral language skills in reading and listening comprehension of text: a comparison of monolingual (L1) and bilingual (L2) speakers of English language. Journal of Research in Reading, 37, S22-S47. http://doi.org/10.1111/j.1467-9817.2012.01538.x

Babayiğit, S. (2015). The relations between word reading, oral language, and reading comprehension in children who speak English as a first (L1) and second language (L2): a multigroup structural analysis. Reading and Writing, 28, 527-544. http://doi.org/10.1007/s11145-014-9536-x

Bishop, D. V. M. (2003). Test for reception of grammar version 2 (TROG-2). London: Pearson Assessment. Browne, M. W., \& Cudeck, R. (1993). Alternative ways of assessing model fit. In K. A. Bollen \& J. S. Long (Eds.), Testing structural equation models (pp. 136-162). Newbury Park, CA: Sage.

Bowyer-Crane, C., Fricke, S., Schaefer, B., Lervåg, A., \& Hulme, C. (2017). Early literacy and comprehension skills in children learning English as an additional language and monolingual children with language weaknesses. Reading and Writing, 30, 771-790. http://doi.org/10.1007/s11145-0169699-8

Burgoyne, K., Whiteley, H. E., \& Hutchinson, J. M. (2010). The development of comprehension and reading-related skills in children learning English as an additional language and their monolingual, English-speaking peers. British Journal of Educational Psychology, 81, 344-354. http://doi.org/10.1348/000709910x504122

Cain, K., \& Bignell, S. (2014). Reading and listening comprehension and their relation to inattention and hyperactivity. British Journal of Educational Psychology, 84, 108-124. doi:10.1111/bjep.12009 CILT (2012). Centre for information on language teaching and research (2005). Languages in schools. Retrieved from http://www.naldic.org.uk/research-and-information/eal-statistics/lang 
Curtis, M. E. (1980). Development of components of reading skills. Journal of Educational Psychology, 72, 656-669. doi:10.1037/0022-0663.72.5.656

Demie, F. (2017). English as an additional language and attainment in primary schools in England. Journal of Multilingual and Multicultural Development, $0(0), 1-14$. http://doi.org/10.1080/01434632.2017.1348508

Department for Education. (2016). Statistical First Release: National curriculum assessments at key stage 2 in England: SFR 62/ 2016. London, UK.

Department for Education. (2017). Statistical First Release: Schools, pupils and their characteristics. SFR 28/2017. London, UK.

Dunn, L. M., Dunn, D., \& National Foundation for Educational Research (2009). The British Picture Vocabulary Scale - 3 (Third ed.). London: GL Assessment.

Enders, C. K., \& Bandalos, D. L. (2001). The relative performance of full information maximum likelihood estimation for missing data in structural equation models. Structural Equation Modeling, 8, 430-457. http://www.tandfonline.com/doi/abs/10.1207/S15328007SEM0803_5

Farnia, F., \& Geva, E. (2011). Cognitive correlates of vocabulary growth in English language learners. Applied Psycholinguistics, 32, 711-738. http://doi.org/10.1017/S0142716411000038

Farnia, F., \& Geva, E. (2013). Growth and predictors of change in English language learners' reading comprehension. Journal of Research in Reading, 36, 389-421. http://doi.org/10.1111/jrir.12003

Foster, H. (2007). Single word reading test 6-16. London: GL Assessment.

Geva, E. (2006). Second-language Oral Proficiency and Second-Language Literacy. In D. August \& T. Shanahan (Eds.), Developing Literacy in Second-language Learners (Vol. 5, pp. 123-144). Mahwah, New Jersey: Lawrence Erlbaum Associates.

Geva, E., \& Farnia, F. (2012). Developmental changes in the nature of language proficiency and reading fluency paint a more complex view of reading comprehension in ELL and EL1. Reading and Writing, 25, 1819-1845. http://doi.org/10.1007/s11145-011-9333-8

Gottardo, A., Mirza, A., Koh, P. W., Ferreira, A., \& Javier, C. (2018). Unpacking listening comprehension: the role of vocabulary, morphological awareness, and syntactic knowledge in reading comprehension. Reading and Writing, 31, 1741-1764. https://doi.org/10.1007/s11145-017-9736-2

Gough, P. B., Hoover, W. A., \& Peterson, C. L. (1996). Some observations on a simple view of reading. In J. Oakhill \& C. Cornoldi (Eds.), Reading comprehension difficulties: Processes and interventions (pp. 1-13). Mahwah, NJ: Erlbaum. 
Gough, P. B., \& Tunmer, W. E. (1986). Decoding, reading and reading disability. Remedial and Special Education, 7, 6-10. http://doi.org/10.1177/074193258600700104

Hayes, A., \& Scharkow, M. (2013). The relative trustworthiness of inferential tests of the indirect effect in statistical mediation analysis: Does method really matter? Psychological Science, 24, 1918.

Hillert, D., \& Nakano, Y. (2016). Second language sentence processing: Psycholinguistic and neurobiological research paradigms Methods in bilingual reading comprehension research (pp. 231263): Springer.

Hoover, W. A., \& Gough, P. B. (1990). The simple view of reading. Reading and Writing, 2, 127-160. doi:10.1007/bf00401799

Hogan, T. P., Adlof, S. M., \& Alonzo, C. N. (2014). On the importance of listening comprehension. International Journal of Speech-Language Pathology, 16, 199-207. http://doi.org/10.3109/17549507.2014.904441

Hutchinson, J. M., Whiteley, H. E., Smith, C. D., \& Connors, L. (2003). The developmental progression of comprehension-related skills in children learning EAL. Journal of Research in Reading, 26, 19-32. http://doi.org/10.1111/1467-9817.261003

Joshi, R. M., \& Aaron, P. G. (2000). The component model of reading: Simple view of reading made a little more complex. Reading Psychology, 21(2), 85-97. https://doi.org/10.1080/02702710050084428

Joshi, R. M., Tao, S., Aaron, P. G., \& Quiroz, B. (2012). Cognitive component of componential model of reading applied to different orthographies. Journal of Learning Disabilities, 45, 480-486. doi: $10.1177 / 0022219411432690$

Kline, R. B. (2011). Principles and practice of structural equation modeling (3 ed.). London: The Guildford Press.

Kintsch, W., \& Rawson, K. A. (2005). Comprehension. In M. Snowling \& C. Hulme (Eds.), The science of reading: a hand book (pp. 209-226). London: Blackwell.

Language and Reading Research Consortium (2017). Oral language and listening comprehension: same or different constructs? Journal of Speech, Language, and Hearing Research, 60, 1273-1284. doi:10.1044/2017_JSLHR-L-16-0039

Lervåg, A., \& Aukrust, V. G. (2010). Vocabulary knowledge is a critical determinant of the difference in reading comprehension growth between first and second language learners. Journal of Child Psychology and Psychiatry, 51, 612-620. doi:10.1111/j.1469-7610.2009.02185.x 
Lervåg, A., Hulme, C., \& Melby-Lervåg, M. (2017). Unpicking the Developmental Relationship Between Oral Language Skills and Reading Comprehension: It's Simple, But Complex. Child Development. Advance online publication. http://doi.org/10.1111/cdev.12861

Lesaux, N. K., Rupp, A. A., \& Siegel, L. S. (2007). Growth in reading skills of children from diverse linguistic backgrounds: Findings from a 5-year longitudinal study. Journal of Educational Psychology, 99, 821-834. http://doi.org/10.1037/0022-0663.99.4.821

Lesaux, N. K., \& Siegel, L. S. (2003). The Development of Reading in Children Who Speak English as a Second Language. Developmental Psychology, 39, 1005-1019. http://doi.org/10.1037/00121649.39.6.1005

Lesaux, N., Lipka, O., \& Siegel, L. (2006). Investigating Cognitive and Linguistic Abilities that Influence the Reading Comprehension Skills of Children from Diverse Linguistic Backgrounds. Reading and Writing, 19, 99-131. http://doi.org/10.1007/s11145-005-4713-6

Mancilla-Martinez, J., \& Lesaux, N. K. (2011). The Gap Between Spanish Speakers’ Word Reading and Word Knowledge: A Longitudinal Study. Child Development, 82, 1544-1560. http://doi.org/10.1111/j.1467-8624.2011.01633.x

Melby-Lervåg, M., \& Lervåg, A. (2014). Reading comprehension and its underlying components in secondlanguage learners: A meta-analysis of studies comparing first- and second-language learners.

Psychological Bulletin, 140, 409-33. http://doi.org/10.1037/a0033890

Nagy, W. E., Anderson, R. C., \& Herman, P. A. (1987). Learning Word Meanings From Context During Normal Reading. American Educational Research Journal, 24, 237-270.

http://doi.org/10.3102/00028312024002237

NICHD (2005). Pathways to reading: The role of oral language in the transition to reading. Developmental Psychology, 41, 428-442. doi:10.1037/0012-1649.41.2.428

Pasquarella, A., Chen, X., Gottardo, A., \& Geva, E. (2015). Cross-language transfer of word reading accuracy and word reading fluency in Spanish-English and Chinese-English bilinguals: Script-universal and script-specific processes. Journal of Educational Psychology, 107, 96.

Perfetti, C. A., Landi, N., \& Oakhill, J. (2005). The acquisition of reading comprehension skills. In M. Snowling \& C. Hulme (Eds.), The science of reading: A handbook (pp. 227-247). Oxford: Blackwell.

Pressley, M., \& Gaskins, I. W. (2006). Metacognitively competent reading comprehension is constructively responsive reading: how can such reading be developed in students? Metacognition Learning, 1, 99113.

Proctor, P. C., Carlo, M., August, D., \& Snow, C. (2005). Native Spanish-speaking children reading in English: Towards a model of comprehension. Journal of Educational Psychology, 97, 245-256. doi:10.1037/0022-0663.97.2.246. 
Proctor, C. P., Dalton, B., \& Grisham, D. L. (2007). Scaffolding English Language Learners and Struggling Readers in a Universal Literacy Environment with Embedded Strategy Instruction and Vocabulary Support. Journal of Literacy Research, 39, 71-93. https://doi.org/10.1080/10862960709336758

Snowling, M. J., Stothard, S. E., Clarke, P., Bowyer-Crane, C., Harrington, A., Truelove, E., ... \& Hulme, C. (2009). YARC York Assessment of Reading for Comprehension Passage Reading. GL Publishers.

Strand, S., Malmberg, L., \& Hall, J. (2015). English as an Additional Language (EAL) and educational achievement in England: An analysis of the National Pupil Database. Retrieved from https://ore.exeter.ac.uk/repository/bitstream/handle/10871/23323/EAL_and_educational_achievement2. pdf? sequence $=1$

Trapman, M., van Gelderen, A., van Steensel, R., van Schooten, E., \& Hulstijn, J. (2014). Linguistic knowledge, fluency and meta-cognitive knowledge as components of reading comprehension in adolescent low achievers: differences between monolinguals and bilinguals. Journal of Research in Reading, 37, S3-S21. http://doi.org/10.1111/j.1467-9817.2012.01539.x

van Gelderen, A., Schoonen, R., de Glopper, K., Hulstijn, J., Snellings, P., Simis, A., \& Stevenson, M. (2003). Roles of linguistic knowledge, metacognitive knowledge and processing speed in L3, L2 and L1 reading comprehension. International Journal of Bilingualism, 7, 7-25. http://doi.org/10.1177/13670069030070010201

van Steensel, R., Oostdam, R., van Gelderen, A., \& van Schooten, E. (2014). The role of word decoding, vocabulary knowledge and meta-cognitive knowledge in monolingual and bilingual low-achieving adolescents' reading comprehension. Journal of Research in Reading, 39, 312-329. http://doi.org/10.1111/1467-9817.12042

Wechsler, D. (2004). Wechsler intelligence scale for children- Fourth UK Edition (WISC-IV UK) UK: Pearson.

Whiteside, K. E., Gooch, D., Holloway, R., \& Norbury, C. F. (2016). English Language Proficiency and Early School Attainment Among Children Learning English as an Additional Language. Child Development, 88, 812-827. http://doi.org/10.1111/cdev.12615 
Table 1

Descriptive statistics by language group

\begin{tabular}{|c|c|c|c|c|c|c|c|c|c|}
\hline Measure/ & Group & $n$ & $M$ & $S D$ & Actual & Skewness & Kurtosis & $d$ & $\eta_{p}^{2}$ \\
\hline Possible range & & & & & range & & & & \\
\hline Reading & EL1 & 74 & 85.40 & 6.76 & $69-100$ & -1.14 & -0.17 & $0.54 * *$ & $.23 * *$ \\
\hline \multicolumn{10}{|c|}{ Comprehension / } \\
\hline \multicolumn{10}{|l|}{$69-130$} \\
\hline & EAL & 133 & 81.78 & 6.33 & $69-94$ & -0.54 & -1.51 & & \\
\hline Listening & EL1 & 74 & 2.41 & 1.48 & $0-5.50$ & -0.52 & -1.58 & $0.42 *$ & $.02 *$ \\
\hline \multicolumn{10}{|c|}{ Comprehension / } \\
\hline \multicolumn{10}{|l|}{$0-8$} \\
\hline & EAL & 134 & 1.80 & 1.33 & $0-5.75$ & 1.01 & -1.95 & & \\
\hline
\end{tabular}




\begin{tabular}{|c|c|c|c|c|c|c|c|c|c|}
\hline Measure/ & Group & $n$ & $M$ & $S D$ & Actual & Skewness & Kurtosis & $d$ & $\eta_{p}{ }^{2}$ \\
\hline Possible range & & & & & range & & & & \\
\hline Word Recognition / & EL1 & 74 & 45.11 & 9.76 & $9-56$ & -6.35 & 6.69 & 0.18 & .00 \\
\hline $0-60$ & EAL & 134 & 44.29 & 8.39 & $13-57$ & -6.05 & 4.89 & & \\
\hline Vocabulary / & EL1 & 72 & 126.0 & 15.86 & $77-155$ & 0.90 & 1.39 & $0.84 * *$ & $.37 * *$ \\
\hline $0-168$ & EAL & 132 & 109.3 & 19.2 & $60-149$ & 1.72 & -0.56 & & \\
\hline \multirow{3}{*}{$\begin{array}{l}\text { Grammatical Skills / } \\
0-80\end{array}$} & EL1 & 74 & 70.45 & 8.97 & $32-80$ & -1.30 & 1.64 & $0.73 * *$ & $.37 * *$ \\
\hline & & & & & & & & & \\
\hline & EAL & 133 & 61.27 & 13.19 & $21-78$ & -0.13 & -1.51 & & \\
\hline \multirow{3}{*}{$\begin{array}{l}\text { Matrix Reasoning / } \\
0-35\end{array}$} & EL1 & 72 & 21.22 & 5.41 & $8-34$ & -1.20 & -0.23 & $0.43 * *$ & na \\
\hline & & & & & & & & & \\
\hline & EAL & 133 & 18.83 & 5.52 & $6-32$ & 0.30 & -0.48 & & \\
\hline
\end{tabular}


Note. Raw scores are presented with the exception of reading comprehension, which is based on standard scores. EL1 = English as first language, $\mathrm{EAL}=$ English as an additional language. $d=$ Cohen's $d$ values of $.2, .5$, and .8 are broadly defined as small, medium, large effect sizes, respectively (Cohen, 1988). $\eta_{p}{ }^{2}=$ partial eta $^{2}$, the values of .01, .06 and .14 are defined as small, medium and large, respectively

(Cohen, 1988). The $\eta_{p}{ }^{2}$ values are based on ANCOVA with matrix reasoning as the covariate and the associated $F(1,205)$ values were 29.79, 3.83, 60.74, and 59.21 for reading comprehension, listening comprehension, vocabulary and grammar, respectively.

$* p<.05 . * * p<.01$. 
Table 2

Correlations between the measures by language group

\begin{tabular}{|c|c|c|c|c|c|c|c|}
\hline & 1 & 2 & 3 & 4 & 5 & 6 & 7 \\
\hline 1. Reading comprehension & - & $.60 * *$ & $.59 * *$ & $.51 * *$ & $.44 * *$ & $.33^{*}$ & -.22 \\
\hline 2. Listening comprehension & $.59 * *$ & - & $.39 * *$ & $.43 *$ & $.40 * *$ & $.34 *$ & $-.31 *$ \\
\hline 3. Word recognition & $.54 * * *$ & $.48 * * *$ & - & $.56^{* *}$ & $.62 * *$ & $.48 * *$ & -.06 \\
\hline 4. Vocabulary & $.61 * *$ & $.62 * *$ & $.55^{* *}$ & - & $.54 * *$ & $.42 * *$ & -.02 \\
\hline 5. Grammar & $.61 * *$ & $.57 * *$ & $.42 * *$ & $.52 * *$ & - & $.44 * *$ & .04 \\
\hline 6. Matrix reasoning & $.47 * *$ & $.40 * *$ & $.49 * *$ & $.55^{* *}$ & $.46^{* *}$ & - & -.22 \\
\hline 7. Age & -.07 & .00 & -.04 & -.01 & .05 & -.06 & - \\
\hline
\end{tabular}

as an additional language (EAL, $n=134$ ) below the diagonal. The $p$ value was adjusted to .008 after Bonferroni correction.

$* p<.01 . * * p<.001$ 
Table 3

The Multi-Group Path Model Analysis: Summary of Unstandardised Parameter Estimates

\begin{tabular}{|c|c|c|c|c|c|c|c|c|}
\hline \multirow[t]{2}{*}{ Parameters } & & & \multicolumn{3}{|l|}{ EL1 } & \multicolumn{3}{|l|}{ EAL } \\
\hline & & & UnStd & $S E$ & $p$ & UnStd & $S E$ & $p$ \\
\hline \multicolumn{9}{|l|}{ Direct effects } \\
\hline Vocabulary & $\rightarrow$ & Listening Comprehension & 0.029 & 0.011 & .006 & 0.031 & 0.005 & $<.001$ \\
\hline Grammar & $\rightarrow$ & Listening Comprehension & 0.04 & 0.019 & .031 & 0.034 & 0.007 & $<.001$ \\
\hline Age & $\rightarrow$ & Listening Comprehension & -0.099 & 0.029 & $<.001$ & -0.002 & 0.016 & .906 \\
\hline Listening Comprehension & $\rightarrow$ & Reading Comprehension & 1.882 & 0.42 & $<.001$ & 0.884 & 0.385 & .022 \\
\hline Word Recognition & $\rightarrow$ & Reading Comprehension & 0.255 & 0.076 & $<.001$ & 0.141 & 0.055 & .01 \\
\hline Vocabulary & $\rightarrow$ & Reading Comprehension & 0.061 & 0.046 & .181 & 0.078 & 0.028 & .005 \\
\hline Grammar & $\rightarrow$ & Reading Comprehension & -0.024 & 0.083 & .773 & 0.144 & 0.036 & $<.001$ \\
\hline
\end{tabular}




\begin{tabular}{|c|c|c|c|c|c|c|c|c|}
\hline \multirow[t]{2}{*}{ Parameters } & & \multicolumn{2}{|l|}{ EL1 } & \multicolumn{5}{|c|}{ EAL } \\
\hline & & \multicolumn{2}{|l|}{ UnStd } & $S E$ & $p$ & UnStd & $S E$ & $p$ \\
\hline \multicolumn{9}{|l|}{ Covariances } \\
\hline Vocabulary & $\leftrightarrow$ & Grammar & 74.618 & 18.433 & .001 & 128.54 & 24.554 & $<.001$ \\
\hline Vocabulary & $\leftrightarrow$ & Age & 0.474 & 8.719 & .957 & -1.571 & 8.575 & .855 \\
\hline Grammar & $\leftrightarrow$ & Age & 1.783 & 4.977 & .720 & 3.618 & 5.841 & .536 \\
\hline Word Recognition & $\leftrightarrow$ & Grammar & 53.276 & 11.85 & $<.001$ & 46.081 & 10.309 & $<.001$ \\
\hline Word Recognition & $\leftrightarrow$ & Vocabulary & 84.994 & 20.279 & $<.001$ & 90.777 & 16.036 & $<.001$ \\
\hline Word Recognition & $\leftrightarrow$ & Age & -2.979 & 5.425 & .583 & -1.594 & 3.727 & .669 \\
\hline Matrix Reasoning & $\leftrightarrow$ & Word Recognition & 24.095 & 6.502 & $<.001$ & 22.246 & 4.416 & $<.001$ \\
\hline Matrix Reasoning & $\leftrightarrow$ & Grammar & 21.098 & 5.921 & $<.001$ & 33.284 & 6.858 & $<.001$ \\
\hline Matrix Reasoning & $\leftrightarrow$ & Vocabulary & 35.198 & 10.296 & $<.001$ & 58.725 & 10.467 & $<.001$ \\
\hline Matrix Reasoning & $\leftrightarrow$ & Age & -5.293 & 2.58 & .040 & -1.581 & 1.923 & .411 \\
\hline
\end{tabular}




\begin{tabular}{lccccccc}
\hline Parameters & EL1 & & & EAL & \\
& & & & & \\
& UnStd & $S E$ & $p$ & UnStd & $S E$ & $p$ \\
\hline Variances & & & & & & & \\
Vocabulary & 243.818 & 40.277 & $<.001$ & 370.394 & 45.47 & $<.001$ \\
Grammar & 79.301 & 13.1 & $<.001$ & 171.414 & 21.043 & $<.001$ \\
Word Recognition & 93.988 & 15.526 & $<.001$ & 69.893 & 8.58 & $<.001$ \\
Matrix Reasoning & 28.009 & 4.57 & $<.001$ & 30.042 & 3.684 & $<.001$ \\
Age & 22.852 & 3.775 & $<.001$ & 26.342 & 3.234 & $<.001$ \\
D1 Listening comprehension & 1.443 & 0.238 & $<.001$ & 0.923 & 0.113 & $<.001$ \\
D2 Reading comprehension & 21.506 & 3.553 & $<.001$ & 18.197 & 2.234 & $<.001$
\end{tabular}

Note. EL1 = English as first language; EAL = English as an additional language; UnStd $=$ unstandardised estimate; $\mathrm{D}=$ disturbance (unexplained) variance. 
Table 4

Indirect effects of oral language skills to reading comprehension: Unstandardised estimates (standardised estimates) and 95\% CI

\begin{tabular}{|c|c|c|c|c|}
\hline & \multicolumn{2}{|l|}{ EL1 } & \multicolumn{2}{|l|}{ EAL } \\
\hline & Grammar & Vocabulary & Grammar & Vocabulary \\
\hline \multirow[t]{2}{*}{ Reading comprehension } & .076 & .055 & .030 & .027 \\
\hline & $(.101)$ & $(.129)$ & $(.063)$ & $(.084)$ \\
\hline \multicolumn{5}{|l|}{$95 \% C I$} \\
\hline$L L$ & .010 & .016 & .006 & .005 \\
\hline$U L$ & .175 & .116 & .067 & .057 \\
\hline$p$ & .024 & .004 & .015 & .016 \\
\hline
\end{tabular}

Note. EL1 = English as first language EAL $=$ English as an additional language. The standardised estimates are presented in parentheses. 


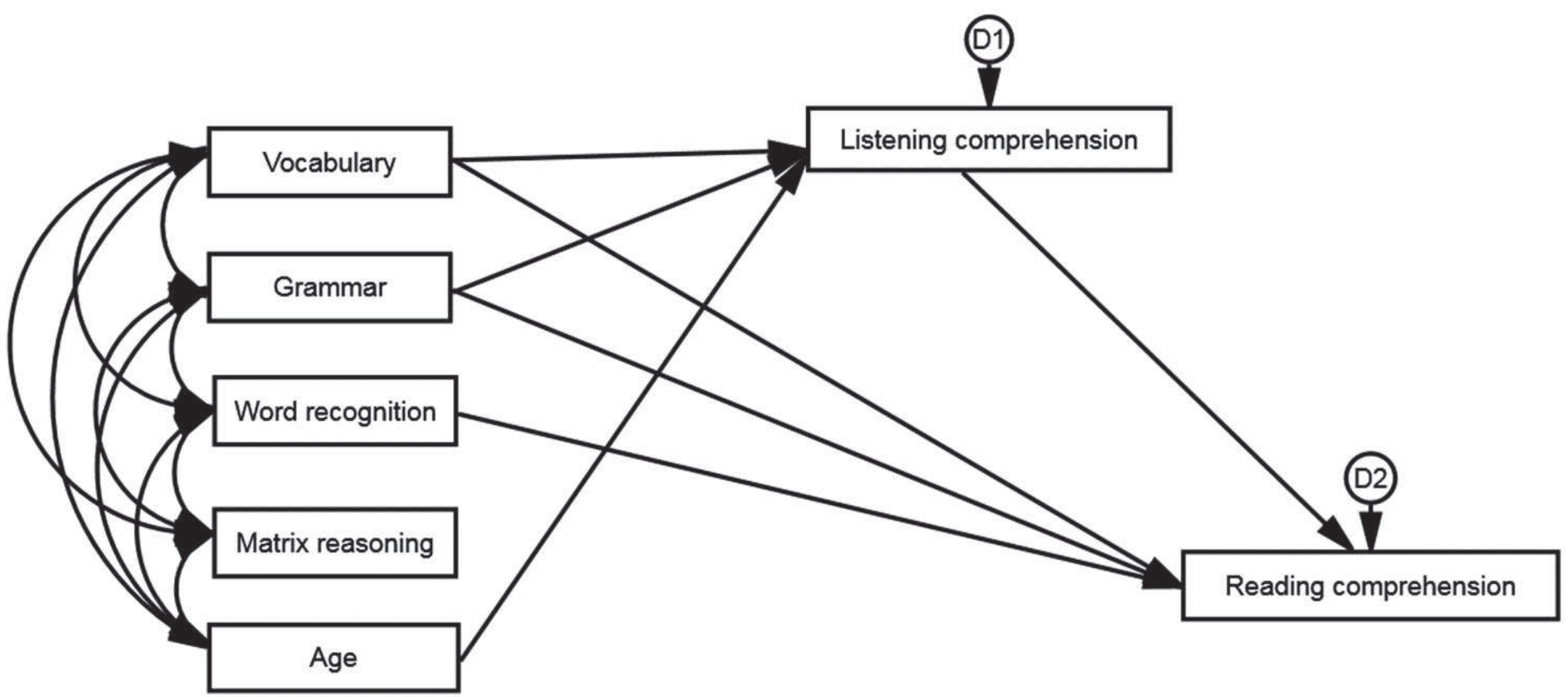

Figure 1. Hypothesised Model. 


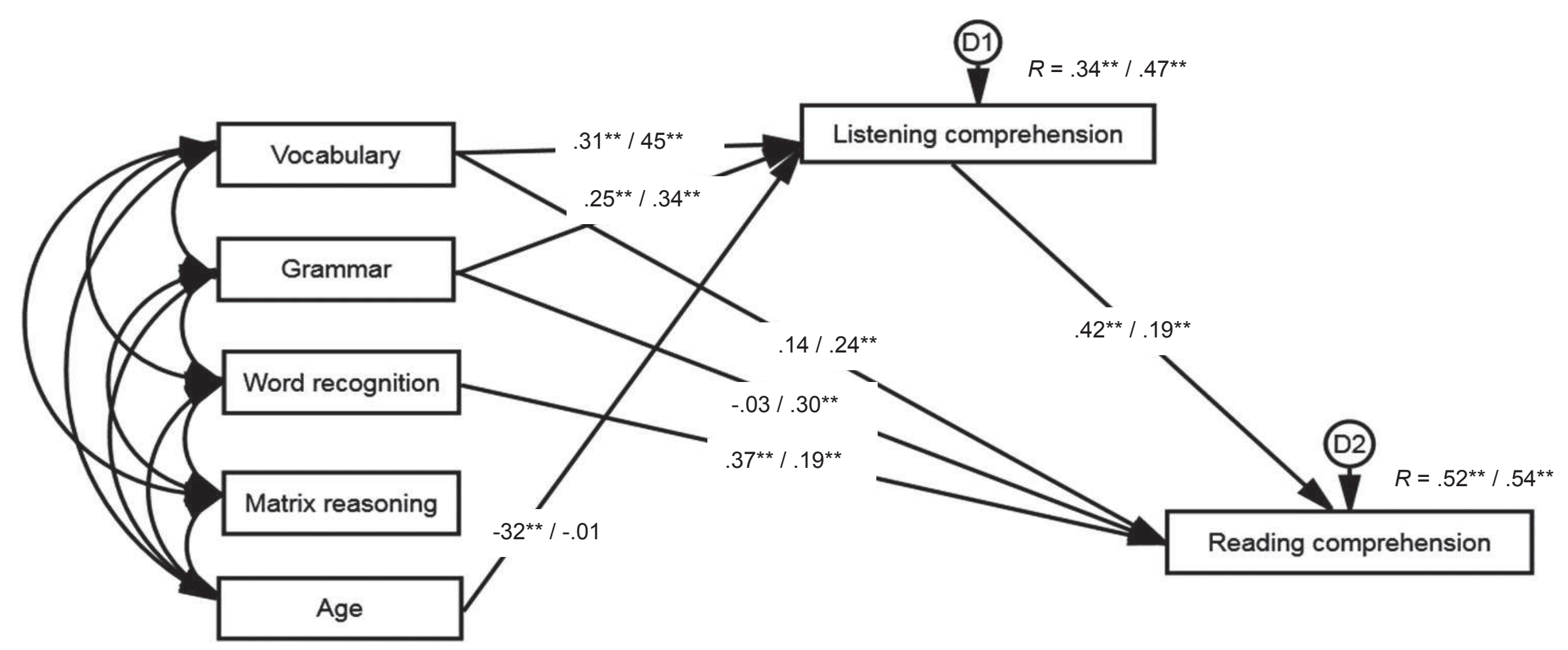


Figure 2. Contributions of vocabulary, grammar, and word recognition to listening comprehension and reading comprehension in learners with English as first language (EL1) and additional language (EAL). The standardised direct path parameters for EL1/ EAL learners. $R^{2}=$ total explained variance.

$* p<.05 . * * p<.01 . * * * p<.001$. 